\title{
Application Of Tactical Style Allocation For Global Equity Portfolios
}

Heng-Hsing Hsieh, Ph.D., CFA, University of the Western Cape, South Africa

Kathleen Hodnett, Ph.D., University of the Western Cape, South Africa

Paul van Rensburg, Ph.D., University of Cape Town, South Africa

\begin{abstract}
Our earlier study suggests that there exists specific timing for the two prominent investment styles, value and momentum. We extend our prior research to test and evaluate a tactical style allocation (TSA) model based on the weighted least squares (WLS) technique for global equities over the outof-sample period from 1994 through 2008. Two TSA style-based portfolios are constructed in this research, namely, a portfolio with the risk-free proxy (cash component), the global momentum index and the global value index as its constituents, and a portfolio that is comprised of only the global momentum index and the global value index. The optimized portfolios based on the TSA model outperform the MSCI World Index, the global value index and the global momentum index on a risk-adjusted basis over the examination period. The cash component of the style-based portfolio appears to provide necessary protection during financial market crises. The results of our study support the use of the proposed TSA model to perform active style rotation between value stocks and momentum stocks for global equity portfolios.
\end{abstract}

Keywords: Tactical Style Allocation; Style Timing; Style Rotation; Value Stocks; Momentum Stocks; Active and Passive Portfolio Management; Value Investing; Momentum Investing; Global Equities

\section{INTRODUCTION}

apital market anomalies such as the value effect, the small firm effect and the momentum effect represent pricing inefficiencies discovered in empirical literature that differentiate security returns in a consistent manner. Investment strategies derived from capital market anomalies form distinctive investment styles pursued by active portfolio managers to differentiate their strategies from those of their rivals. The results of our earlier study suggest that there exists specific timing between value and momentum investment styles in the global equity market (Hsieh and Hodnett, 2012). The value-momentum timing, to a certain degree, is predictable by observing the co-movements of macroeconomic variables (Hsieh, Hodnett and van Rensburg, 2012). These findings motivate for the development of a style timing model that tactically allocates capital between value stocks and momentum stocks in a global equity portfolio to capture the dynamic timing of the two pronounced investment styles in the global equity market.

Adopting the weighted least squares (WLS) technique that places higher weights on more recent information, we attempt to predict the monthly optimal compositions of different investment styles in the global style-based equity portfolio over the period from 01 January 1994 to 31 December 2008 (a total of 180 months). The performance of the style-based global equity portfolios constructed based on this tactical style timing (TSA) model are subsequently evaluated against the performance of the market proxy and the stand-alone style indexes over the examination period. A global equity portfolio developed from a successful TSA model should be resilient during turbulent times and maintain sufficient momentum during the upswing of the economic cycle. The TSA model is applied to two style-based portfolios, one which includes the risk-free cash component in its allocation, and the other which is only optimized with the global momentum index and the global value index. These two portfolios are constructed to test whether the cash component is an important element in mitigating systematic risk in the global equity portfolio during turbulent times. The ultimate goal of this research is to improve the risk-adjusted performance of global equity portfolios and hedge fund strategies throughout different phases of the global economic cycle. The findings of this research provide insights into the applications of TSA models in active 
portfolio management, practical risk management techniques based on investment style diversification and future development of market timing models for hedge fund strategies.

\section{LITERATURE REVIEW}

The primary objective of tactical style allocation (TSA) models is to predict the timing of shifts in major investment styles. Style allocation strategies based on TSA models periodically adjust their allocations among major investment styles in order to tilt their performances towards the best performing investment styles throughout different phases of the economic cycle. Kao and Shumaker (1999) explore the potential benefits of TSA models in the U.S. equity market over the period from 1979 to 1997. They test the effect of perfect monthly switches between alternative investment styles such as value versus growth, large caps versus small caps and equity versus bonds. Results reveal that switching between equity and bonds deliver the highest risk-adjusted returns over other timing strategies. The authors conduct further tests to investigate the potential benefits of style timing for the market neutral strategy with perfect foresight in swapping the long and short positions in alternative styles. The results indicate that there are significant return potential for all 3 strategies. However, the return spread available for switching between equity and bonds have deteriorated drastically since the late 1980s. Kao and Shumaker (1999) suggest that the decline in the potential for the strategy could be due to the declining volatility in the equity and bond markets, increasing popularity of derivatives and increasing correlation between equity and bond returns over time. They also find that when value stocks outperform growth stocks, they tend to have larger spreads than when growth stocks outperform value stocks. The asymmetrical size of the value and growth spread is also documented by Bauman, Conover and Miller (1998) for non-U.S. stock markets. In addition, a strong seasonality of the value-growth spread is found in that the significant value premium is observed in the first quarter of the calendar year, while the value premium turns significantly negative in the last quarter of the calendar year, on average, over the examination period.

Once the potential benefits of style timing are confirmed by the results of their empirical tests, Kao and Shumaker (1999) conduct further tests to determine whether the timing of switch between the value and growth investment styles can be predicted by the co-movements of macroeconomic factors. They suggest that the return differences between these two investment styles are likely to be driven by economic fundamentals throughout the economic cycle. The 7 macroeconomic factors examined by their study include the yield-curve spread, the real bond yield, the corporate credit spread, the high-yield spread, the forecasted GDP growth, the earnings-yield gap and the historical CPI. The test results indicate that the yield-curve spread, the real bond yield and the forecasted GDP growth are positively correlated with the 12-month forward value premium. By contrast, the earnings-yield gap appears to be negatively correlated with the 12-month forward value premium.

Amenc, Malaise, Martellini and Sfeir (2003) test the feasibility of applying style timing strategies on a market neutral hedge fund comprised of the S\&P style indexes over the period from 2000 to 2002. The style timing strategy is determined by the predictions of a multifactor model with style attributes as its inputs. The style indexes used for the optimization procedure include the S\&P 500 Index (large cap), the S\&P Large Cap Growth Index, the S\&P Large Cap Value Index and the Russell 2000 Index (small cap). The results reveal that the S\&P Value Index is the single most important style index in the allocation over the examination period. By contrast, the S\&P Growth Index is held short in most of the months. This evidence supports the argument of Kao and Shumaker (1999) that the rotation between value and growth investment styles is the most effective style rotation. Overall, the market neutral fund developed is found to outperform the S\&P 500 Index with substantially low historical drawdowns.

The profitability of style timing strategies is also examined by Mutooni and Muller (2007) on South African stocks traded on the JSE Securities Exchange over the period from 1994 to 2006. Back-testing results show that a style rotation strategy between the value index and the growth index could be developed based on the yield curve spread, the corporate credit spread, the earnings-yield gap, the equity risk premium, the inflation rate, the index of coincident economic indicators, changes in the money supply, the market returns and the index of economic leading indicators. Hsieh and Hodnett (2012) conduct performance attribution on the value-momentum spread of global equities comprising the Dow Jones (DJ) Sector Titans Composite Index over the period from 01 January 1991 to 31 December 2008. Test results indicate that value stocks tend to underperform momentum stocks 4-6 months prior to the market peak and outperform momentum stocks during turbulent times. Further research on the determinants of the global value-momentum spread indicate that the global value-momentum spread is negatively 
correlated with the industrial production growth of advanced economies and positively correlated with the U.S. dollar strength (Hsieh, Hodnett and van Rensburg, 2012).

\section{METHODOLOGY}

The global momentum index and the global value index constructed in Hsieh and Hodnett (2012) are adapted in this research. Using the global momentum index and the global value index as constituent indexes, a long-only style-based global equity portfolio is first constructed as the base portfolio. In addition to the base portfolio, a long-only portfolio that includes investment in the risk-free asset, in addition to the two style indexes as its constituents, is developed to test the importance of the cash component in the first portfolio. Using the 3-month U.S. Treasuries as the proxy for the risk-free asset, the return on the style-based portfolio $P$ comprised of the prespecified indices in month $t$ is computed using Equation 1. On the other hand, the $T$-month standard deviation for the style-based portfolio $P$ is computed using Equation 2:

$$
\begin{aligned}
& r_{P, t}=\left(w_{P, T B}^{*} \times r_{T B, t}\right)+\left({ }^{*} w_{P, \text { Mom }} \times r_{\text {Mom }, t}\right)+\left({ }^{*} w_{P, \text { Value }} \times r_{\text {Value }, t}\right) \\
& \sigma_{P}=\sqrt{\frac{\sum_{t=1}^{T}\left(r_{P, t}-R_{P}\right)^{2}}{T-1}}
\end{aligned}
$$

Where:

$$
\begin{aligned}
& r_{p, t} \\
& r_{P, t}, r_{T B, t}, r_{\text {Mom }, t} \text { and } r_{\text {Value }, t} \\
& { }^{*} \quad * \quad * \\
& w_{P, T B}, w_{P, \text { Mom }} \text { and } w_{P, \text { Value }} \\
& R_{P} \\
& T
\end{aligned}
$$

Based on the return and the standard deviation of the style-based portfolio computed in Equation 1 and Equation 2, the Sharpe ratio of the style-based portfolio $P$ can thus be computed using Equation 3:

$$
{\text { Sharpe } \text { Ratio }_{P}}=\frac{r_{P}-r_{T B}}{\sigma_{P}}
$$

Using the weighted least squares (WLS) technique, a series of rolling 36-month (month $t$-36 through month t) WLS regressions are performed monthly for the long-only base portfolio over the period from 01 January 1991 through 31 December 2008 to estimate the optimal style allocations (weights) in Equation 1 that will maximize the Sharpe ratio in Equation 3. The optimal style allocations estimated by WLS regressions are subsequently employed to perform style allocations for the forward month $(t+1)$. Such monthly rebalancing procedure is repeated until the optimal monthly style allocations from 01 January 1994 through 31 December 2008 are estimated. The objective of this training process for the TSA strategies is to find the portfolio compositions that maximize the in-sample Sharpe ratios for the respective TSA strategies.

\section{RESULTS}

The out-of-sample time-series portfolio compositions for the long-only base portfolio over the period from 01 January 1994 to 31 December 2008 are illustrated in Figure 1. Although the TSA model allocates substantial weight to the global momentum index in the late 1990s, the allocation to the momentum index gradually declines towards the peak of the I.T. bubble in 2000, which is an indication of the abnormally high volatility of the global 
momentum index during this period. Another period of heavy allocations in the global momentum index is during the late 2000s. However, the TSA model does not remove the allocations in momentum stocks during the market crash of 2008, indicating that the global momentum index is more mean-variance efficient compared to the global value proxy during this period. The global momentum proxy achieves higher returns for similar risk than the global value proxy prior to the market crash. This might be due to the fact that the impact of the market crash in 2008 is not exclusive to momentum stocks as it is during the burst of the I.T. bubble in 2000, but rather a spill-over phenomenon. Thus, the portfolio compositions obtained from the global long-only optimization have failed to protect the portfolio value during the global financial crisis in 2008. The inclusion of the cash component in the optimization procedure has a potential to avoid unwanted exposures in the equity market during the global financial crisis.

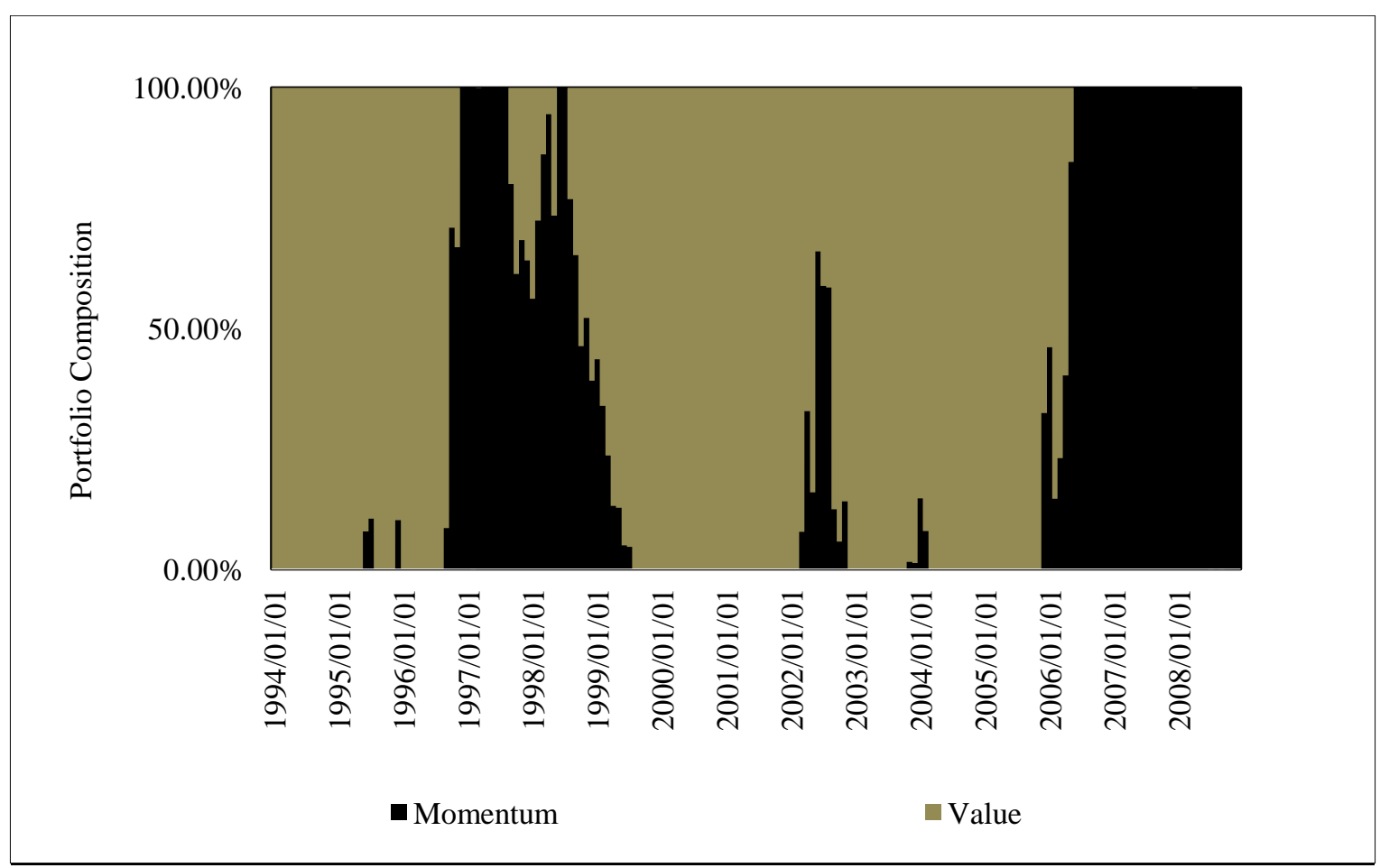

Figure 1: Portfolio Composition (Momentum Index and Value Index)

Figure 2 demonstrates the out-of-sample time-series portfolio composition for the long-only portfolio with the inclusion of the cash component in the optimization procedure. The cash component, proxied by the 3-month U.S. Treasuries, is indicated by the brick-filled area in Figure 2. By incorporating the cash component in the optimization procedure, the TSA model allocates significant amounts of capital to cash during major declines of the global equity markets, which includes the Asian financial crisis in 1998, the global downturn led by the crash of the I.T. bubble in early 2000s and the subprime crisis which led to the global downturn in 2007 and 2008 . The similarity between the base portfolio and the portfolio with cash component is that both portfolios rely heavily on the global value index in their compositions over the examination period. This suggests that the global value index is more mean-variance efficient over the long-run. The global momentum index only plays a role in the long-only optimization procedure closer to the peak of the global equity market. In addition, cash holding is regarded as the most mean-variance efficient allocation during economic downturns. The inclusion of cash in the optimization procedure has the potential to reduce the portfolio variance through diversification since the return of the risk-free proxy is least correlated with the returns of the remaining index constituents in the portfolio. 


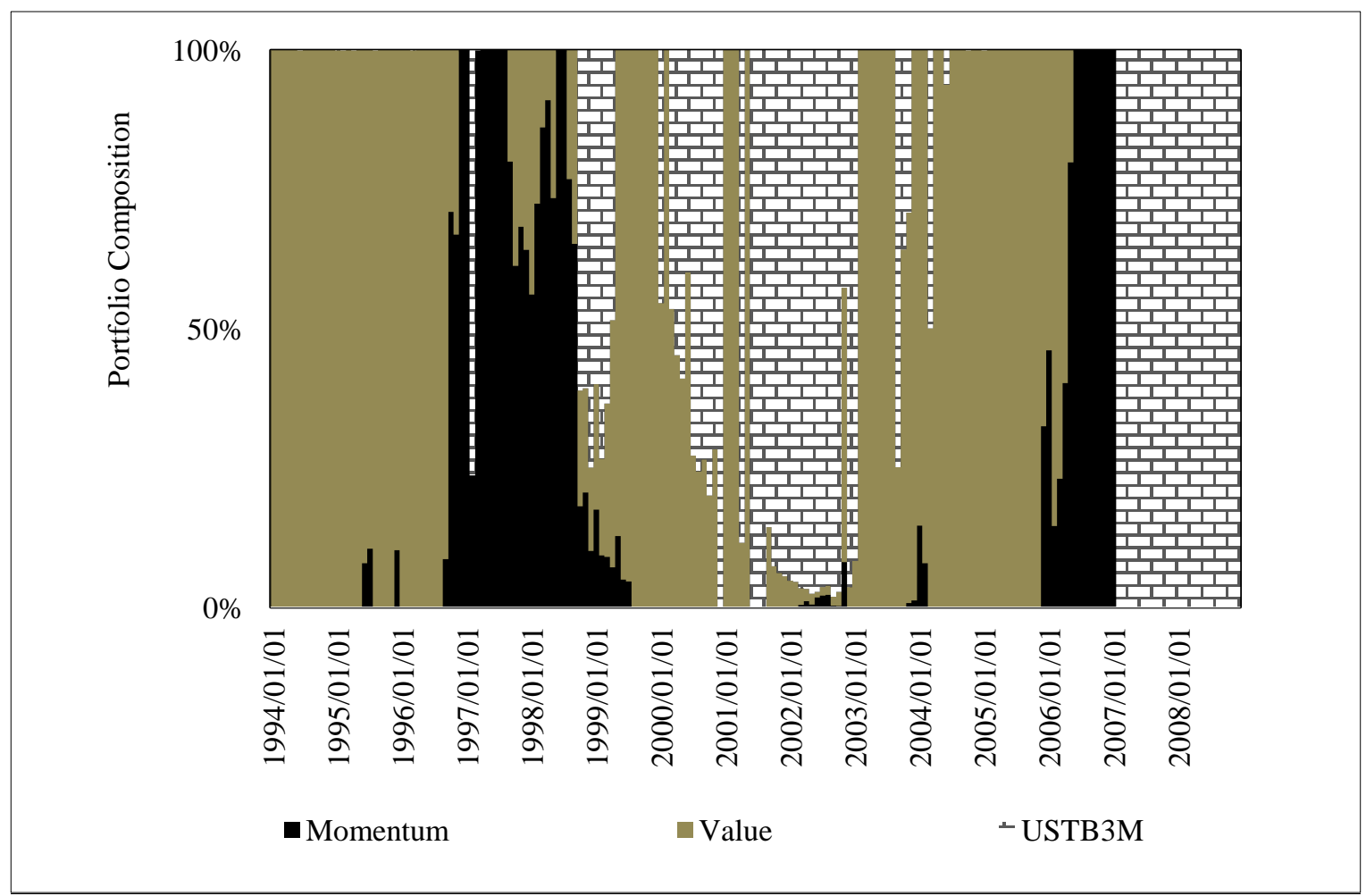

Figure 2: Portfolio Composition (Momentum Index, Value Index and Treasuries)

The risk-return performance statistics of the style-based portfolios and their respective benchmarks are summarized in Table 1. The annualized performance statistics of the market proxy (MSCI World Index), the riskfree proxy (USTB3M) and the constituent global style indexes employed in the optimization procedure are demonstrated on the left-hand side of the table. The performance statistics of the two global style-based portfolios are demonstrated on the right-hand side of the table. The return aspect of the portfolios is evaluated by the annualized geometric return, arithmetic return and the cumulative returns over the period from 01 January 1994 through 31 December 2008. The risk aspect of the portfolios is evaluated based on the annualized standard deviation and the beta coefficient. Three reward-to-risk measures used to evaluate the risk-adjusted performance of the portfolios include the Sharpe ratio, Treynor measure and Jensen's alpha. The $R$-squared of the regression used to estimate Jensen's alpha and the beta coefficient of the capital asset pricing model (CAPM) is provided in Table 1.

The examination of the return aspect of the performance statistics reveal that both style-based TSA portfolios outperform all of the benchmarks in terms of the geometric return, arithmetic return, and cumulative returns over the examination period. The introduction of the cash component in the style-based TSA portfolio does not hamper the returns of the portfolio.

With regard to the risk aspect of the performance statistics, the momentum index has the highest annualized standard deviation of $20.15 \%$, followed by the style-based TSA portfolio without the cash component (17.31\%). By including the cash component in the optimization procedure, the annualized standard deviation of the TSA portfolio improves to $11.40 \%$, which is the lowest amongst all portfolios under examination. In addition, the beta coefficient of the TSA portfolio with the cash component is only $0.468 \%$, which is substantially lower than the average stock beta of 1.00 .

The TSA portfolio with the cash component also achieves the highest risk-adjusted returns measured in terms of the Sharpe ratio, Treynor measure and Jensen's alpha. Both of the TSA portfolios have statistically significant Jensen's alpha (indicated by their $t$-statistics), which is not achieved by the stand-alone momentum and 
value indexes. Overall, the cash component of the TSA portfolio is proven to be a significant factor in improving the risk-adjusted performance of the global style-based portfolio.

The $R$-squared of the regression in estimating the beta coefficient indicates the percentage of the portfolio returns that is explained by the movements of the market risk premium. The TSA portfolio with the cash component is the only portfolio that has an $R$-squared of less than $50 \%$. This suggests that the cash component has effectively reduced the co-movements between the performance of the style-based TSA portfolio and that of the market. In summary, the cash component of the style-based portfolio serves to mitigate the adverse impact of financial market crises over the examination period without hampering the upside profit potential during the upswings of the economic cycle.

Table 1: Performances Statistics

\begin{tabular}{|c|c|c|c|c|c|c|}
\hline & \multicolumn{4}{|c|}{ Benchmarks } & \multicolumn{2}{|c|}{ Global TSA Strategies } \\
\hline & $\begin{array}{l}\text { MSCI } \\
\text { World } \\
\end{array}$ & USTB3M & Momentum & Value & $\begin{array}{c}\text { Style-Based TSA } \\
\text { (without Cash) }\end{array}$ & $\begin{array}{c}\text { Style-Based TSA } \\
\text { (with Cash) }\end{array}$ \\
\hline Geometric Return & $4.99 \%$ & $3.86 \%$ & $13.03 \%$ & $11.91 \%$ & $14.90 \%$ & $15.31 \%$ \\
\hline $\begin{array}{l}\text { Cumulative } \\
\text { Return }\end{array}$ & 2.077 & 1.765 & 6.282 & 5.410 & 8.03 & 8.47 \\
\hline Arithmetic Return & $6.22 \%$ & $3.86 \%$ & $15.31 \%$ & $13.58 \%$ & $16.63 \%$ & $16.04 \%$ \\
\hline Standard Deviation & $15.10 \%$ & $0.49 \%$ & $20.15 \%$ & $17.08 \%$ & $17.31 \%$ & $11.40 \%$ \\
\hline Sharpe Ratio & $7.52 \%$ & N/A & $45.53 \%$ & $47.15 \%$ & $63.79 \%$ & $100.43 \%$ \\
\hline $\begin{array}{l}\text { Treynor } \\
\text { Measure }\end{array}$ & $1.14 \%$ & N/A & $8.69 \%$ & $8.08 \%$ & $11.20 \%$ & $24.48 \%$ \\
\hline $\begin{array}{l}\text { Jensen's Alpha } \\
t \text {-Statistic }\end{array}$ & $\begin{array}{r}0.00 \% \\
0.000\end{array}$ & $\begin{array}{l}\text { N/A } \\
N / A\end{array}$ & $\begin{array}{c}8.95 \% \\
1.298\end{array}$ & $\begin{array}{c}7.36 \% \\
1.434\end{array}$ & $\begin{array}{c}10.44 \% \\
2.508\end{array}$ & $\begin{array}{c}11.07 \% \\
3.566\end{array}$ \\
\hline Beta & 1.00 & 0.00 & 1.056 & 1.00 & 0.986 & 0.468 \\
\hline$R$-Squared & $100 \%$ & $0.00 \%$ & $62.61 \%$ & $78.21 \%$ & $74.16 \%$ & $37.75 \%$ \\
\hline
\end{tabular}

\section{CONCLUSION}

The two prominent investment styles in the global equity market, namely the value effect and the momentum effect are closely related to investor sentiment, which in turn is driven by the state of the economy. Towards the peak of the economic cycle, investors tend to be over-optimistic regarding stocks with superior recent performance and neglect stocks that temporary underperform. This phenomenon leads momentum stocks to outperform value stocks prior to the market peak, and the reversal is likely to occur in the subsequent market corrections. 
Based on the above argument, we construct two global styled-based equity portfolios that rebalance monthly based on the optimal style allocations predicted by the TSA model to determine whether profitable investment strategies could be developed based on the observed value-momentum spread. The two portfolios are different in terms of whether they have a cash component in their portfolio composition. Should the introduction of the cash component be successful, the portfolio with the cash component should be able to provide a safety cushion during turbulent times without sacrificing upside return potential significantly.

Adopting the WLS regressions that estimate the optimal style allocations over the past 36-month training period, the estimated monthly style allocations are implemented over the out-of-sample period from 01 January 1994 through 31 December 2008. The two major financial crises over the examination period include the crash of the I.T. bubble in 2000 and the global financial market crisis towards the end of 2008. The examination of the style allocations of the two TSA portfolios reveals that the value investment style dominates the momentum investment style over the examination period. The equity allocation is successfully replaced by allocation to the U.S. Treasuries during major financial crises over the examination period. The evaluation of the risk-return characteristics of the portfolios shows that both TSA style-based portfolios are more mean-variance efficient compared to the MSCI World Index and the stand-alone global momentum and value indexes. When the cash component is included in the optimization procedure, the TSA portfolio yields significant improvement in terms of both its risk and return, making the portfolio more resilient during turbulent times. The findings of this paper provide grounds for future development of TSA models based on WLS regressions.

\section{ACKNOWLEDGEMENT}

This work is supported by the National Research Foundation of South Africa. We wish to thank the Research Office and the School of Business and Finance of the University of the Western Cape for their support.

\section{AUTHOR INFORMATION}

Dr. Heng-Hsing Hsieh, CFA is the Head of Finance in the School of Business and Finance at the University of the Western Cape, South Africa. He is a CFA charterholder and a member of the South African Institute of Financial Markets (SAIFM). E-mail: ahsieh@uwc.ac.za. Corresponding Author

Dr. Kathleen Hodnett is currently a Research Fellow (funded by the National Research Foundation (NRF) of South Africa) and a Senior Lecturer in the School of Business and Finance at the University of the Western Cape, South Africa. She is a member of the International Institute of Forecasters (IIF) and an associate of the South African Institute of Financial Markets (SAIFM).

Prof. Paul van Rensburg is the Frank Robb Professor of Finance at the University of Cape Town, South Africa. He is the principal of Salient Quantitative Investment Management.

\section{REFERENCES}

1. Amenc N, Malaise P, Martellini L and Sfeir D (2003), Tactical Style Allocation - A New Form of Market Neutral Strategy, EDHEC Risk and Asset Management Research Centre

2. Baghai-Wadji R and Klocker S (January 2007), Performance and Style Shifts in the Hedge Fund Industry, London Business School, Working Paper, 1-48

3. Banz R W (1981), "The Relationship between Return and Market Value of Common Stocks”, Journal of Financial Economics, no 9, 3-18

4. Basu S (1977), "The Investment Performance of Common Stocks in Relation to Their Price to Earnings Ratio: A Test of the Efficient Markets Hypothesis", Journal of Finance, vol 32, no 3, 663-682

5. Bauman C, Conover C M and Miller R E (1998), "Growth versus Value and Large-Cap versus Small-Cap Stocks in International Markets", Financial Analysts Journal, vol 54, no 2, 75-89

6. Brown P, Kleidon A W and Marsh T A (1983), "New Evidence on the Nature of Size-Related Anomalies in Stock Prices", Journal of Financial Economics, no 12, 33-56

7. Carhart M (1997), "On persistence of mutual fund performance", Journal of Finance, no 52, 57-82

8. Chan K C, Hameed A and Tong W (June 2000), "Profitability of Momentum Strategies in the International Equity Markets", The Journal Financial and Quantitative Analysis, vol 35, no 2, 153-172 
9. Chan L K C and Lakonishok J (January/February 2004), "Value and Growth Investing: Review and Update", Financial Analysts Journal, vol 60, no 1, 71-86

10. Fama E F and French K R (1992), "The Cross-Section of Expected Stock Returns", Journal of Finance, vol 47, 427-465

11. Fama E F and French K R (1993), "Common Risk Factors in the Returns on Stocks and Bonds", Journal of Financial Economics, vol 33 no 1, 3-56

12. Fama E F and French K R (1998), "Value Versus Growth: The International Evidence", Journal of Finance, vol 53, no 6, 1975-1999

13. Forner C and Marhuenda J (2003), "Contrarian and Momentum Strategies in the Spanish Stock Market Seasonality", Journal of Finance, vol 42, no 3, 557-581

14. Fung W and Hsieh D A (1998), "Performance Attribution and Style Analysis: From Mutual Funds to Hedge Funds", Paradigm Financial Products, Principal Publisher

15. Hsieh H and Hodnett K E (2012), "Dissecting the Value-Momentum Spread: Sector Allocation Effect Versus Country Allocation Effect”, Journal of Applied Business Research, vol 28. No 2, 227-236

16. Hsieh H, Hodnett K E and van Rensburg P (2012), "The Influences of Macroeconomic Forces on the Value-Momentum Spread of Global Equities”, International Business and Economics Research Journal, vol 11, no 5, 497-506

17. Ibbotson R D and Kaplan P (2000), "Does Asset Allocation Policy Explain 40, 90, or 100 Percent of Performance?", Financial Analysts Journal, vol 56, no 1, 26-33

18. Jegadeesh N and Titman S (March 1993), "Returns to Buying Winners and Selling Losers: Implications for Stock Market Efficiency", Journal of Finance, vol 48, no 1, 65-91

19. Kao D and Shumaker R D (1999), "Equity Style Timing", Financial Analysts Journal, vol 55, no 1, 37-47

20. Mutooni R and Muller C (2007), "Equity Style Timing”, Investment Analysts Journal, no 65, 15-24

21. Reinganum M R (1981), "Misspecification of Capital Asset Pricing - Empirical Anomalies Based on Earnings' Yields and Market Values”, Journal of Financial Economics, no 9, 19-46

22. Reinganum M R (1983), "The Anomalous Stock Market Behavior of Small Firms in January - Empirical Tests for Tax-Loss Selling Effects", Journal of Financial Economics, no 12, 89-104

23. Schiereck D, De Bondt W F M and Weber M (1999), "Contrarian and Momentum Strategies in Germany", Financial Analysts Journal, vol 55, no 6, 104-116

24. Sharpe W F (1992), "Asset Allocation: Management Style and Performance Measurement", Journal of Portfolio Management, vol 18, 7-19

25. Yu X (2008), Style Indices and Active Portfolio Construction on the JSE, University of Cape Town, Working Paper 